\title{
Therapeutic abortion in Siriraj Hospital: A 10-year review*
}

\author{
Saifon Chawanpaiboon $^{1 *}$, Chanon Neungton ${ }^{2}$ \\ ${ }^{1}$ Division of Maternal-Fetal Medicine, Department of Obstetrics \& Gynecology, Faculty of Medicine Siriraj Hospital, Mahidol Uni- \\ versity, Bangkok, Thailand \\ ${ }^{2}$ Division of Infectious Disease, Department of Obstetrics \& Gynecology, Faculty of Medicine Siriraj Hospital, Mahidol University, \\ Bangkok, Thailand \\ Email: $\underline{\text { siscw@mahidol.ac.th }}$
}

Received 24 May 2013; revised 26 June 2013; accepted 4 July 2013

Copyright (C) 2013 Saifon Chawanpaiboon, Chanon Neungton. This is an open access article distributed under the Creative Commons Attribution License, which permits unrestricted use, distribution, and reproduction in any medium, provided the original work is properly cited.

\section{ABSTRACT}

Objective: To assess indications, methods of interventions and gestational age of women underwent therapeutic abortion. Method: A total of 1381 cases of pregnant women underwent therapeutic abortion with completed charts between $1^{\text {st }}$ January, 2001 to $31^{\text {st }}$ December, 2010, were enrolled in this study. The patient data including demographic data, gestational age of abortion, methods of abortion, dosage of cytotec usage, indications of abortion and length of hospital stay were recorded. RESULT: Mean maternal age, gestational age of abortion and abortus weight were $29.56 \pm 7.09$ years, $17.54 \pm 6.05$ weeks of gestation and 401.27 \pm 269.49 grams, respectively. Induced abortion with cytotec and syntocinon was mostly $(28.3 \%)$ and rarely used (1.3\%), respectively. Dosage of cytotec usage of $\mathbf{4 0 0}$ micrograms every 6 hours regimen was mostly used $(53.1 \%)$. Indications of therapeutic abortion were maternal HIV infection (18.5\%), fetal structural abnormalities (17.7\%) and dead fetus in utero $(19.3 \%)$ and were found. Curettage alone was mostly performed in the indicated patients with gestational age of $9.07 \pm 2.85$ weeks. Medical cytotec and syntocinon alone were mostly performed in the indicated patients with gestational age of $19.51 \pm 4.55$ and $23.94 \pm 4.67$ weeks, respectively. Tubal sterilization and the length of hospital stay were higher in the group of therapeutic abortion with maternal indication. Therapeutic abortion by hysterotomy had higher length of hospital stay than those with curettage method. Conclusion: Indications of therapeutic abortion were mostly from maternal HIV infection, fetal structural abnormalities and

\footnotetext{
"Conflict of interest: The authors declare that no conflicts of interest exist.

${ }^{\#}$ Corresponding author.
}

dead fetus in utero. Medical and surgical interventions were mostly applied during mid and early gestation, respectively.

Keywords: Therapeutic Abortion; Indication; Intervention; Gestational Age

\section{INTRODUCTION}

Therapeutic abortion is defined by the intentional termination of a pregnancy prior to the independently lived fetus. Whenever there are some indications to end a pregnancy, an abortion can be performed. The indications of abortion are the hardship, endanger of maternal life or health, or the results of prenatal tests with severe fetal abnormalities.

The safest time of abortion is within the first trimester because few complications are experienced. Abortion during 13 - 24 weeks has a higher rate of complications. Abortion after 24 weeks of gestation is extremely rare and usually performed in maternal indications.

However, there was no study about therapeutic abortion in Siriraj Hospital, therefore this research was performed. The study is hypothesized that indications of therapeutic abortion 24 weeks or less are mostly related with fetus and those with after 24 weeks are related with mother. The objective of this study was to examine the trend of therapeutic abortion, indications and methods of therapeutic abortion during 10 -year period.

\section{METHODS}

The present cohort study was carried out at Siriraj Hospital, Mahidol University, Bangkok, Thailand, using the completed charts of maternity patients aborted at Siriraj Hospital between January $1^{\text {st }}$, 2001, and December $31^{\text {st }}$, 2010. The study was approved by The Ethics Committee 
of the Faculty of Medicine of Siriraj Hospital; informed consent was not needed, however, because the design was retrospective.

For the 10 years considered, the charts were complete for 1381 women. Demographic data, indications, gestational age and methods of therapeutic abortions were entered in the specially designed data record form. The indications considered were from mother or fetus.

Data were analyzed using SPSS version 14 (IBM, Armonk, NY, USA). The chi-square test and analysis of variance were used to compare categorical variables and continuous variables, respectively. Results were reported as number, percentage, or mean and standard deviation. $\mathrm{P}<0.05$ were considered significant.

\section{RESULTS}

From January $1^{\text {st }}, 2001$, to December $31^{\text {st }}, 2010$, the charts of 1381 patients with therapeutic abortion were collected. Mean maternal age was $29.56 \pm 7.09$ years (Figure 1) with 516 cases of primigravidarum and 431 cases of previous abortion (Table 1). Mean gestational age of abortion was $17.54 \pm 6.05$ weeks of gestation (Figure 2) while mean abortus weight was $401.27 \pm$ 269.49 grams (Figure 3). Among many methods of therapeutic abortion, only cytotec induction was mostly used (28.3\%) and only syntocinon induction was rarely used (1.3\%) (Figure 4). The mean length of hospital stay and those after abortion were $4 \pm 2.58$ and $2.15 \pm 1.77$ days, respectively (Table 1, Figures 5, 6). Tubal sterilization was performed in $24.5 \%$ of cases (Table $\mathbf{1}$ ).

Dosage of cyotec usage for therapeutic abortion, varied from 100 to 400 micrograms every 4 - 8 hours but 400 micrograms every 6 hours regimen was mostly used (53.1\%) (Table 2, Figure 7). Indications of therapeutic abortion were maternal HIV infection (18.5\%), fetal structural abnormalities (17.7\%) and dead fetus in utero (19.3\%), respectively (Table 3). Medical cytotec intervention was mostly used in patient with fetal indication while combined medical cytotec and curettage intervention was mostly used in maternal indication (Figure 8).

Tubal sterilization was mostly performed after therapeutic abortion following maternal indication. (Figure 9) Curettage alone was mostly performed in the indicated patients with gestational age of $9.07 \pm 2.85$ weeks. Medical cytotec and syntocinon alone were mostly used in the indicated patients with gestational age of $19.51 \pm$ 4.55 and $23.94 \pm 4.67$ weeks, respectively (Table 4, Figure 10). Therapeutic abortion from fetal indication was performed at mean gestational age of $21.17 \pm 3.96$ weeks (Table 5).

Total length of hospital stay and those after intervenetions were higher in the group of therapeutic abortion with maternal indication (Figures 11-12). Therapeutic abortion with hysterotomy had the higher length of hos-

Table 1. Demographic and relevant data of therapeutic abortion at Siriraj Hospital.

\begin{tabular}{|c|c|c|}
\hline Demographic and relevant data $(n=1381)$ & Mean \pm SD, meadian (min, max) & n (\%) \\
\hline Maternal age (years) & $29.56 \pm 7.09,30(12,48)$ & \\
\hline Primigravidarum & & $516(37.4)$ \\
\hline Nulliparous & & $692(50.1)$ \\
\hline Previous abortion (s) & & $431(31.2)$ \\
\hline Gestational of abortion (weeks) (n = 1373) & $17.54 \pm 6.05,19(2,33)$ & \\
\hline Abortus weight (n=957) (Exclude multifetal pregnancy) & $401.27 \pm 269.49,370(8,1950)$ & \\
\hline Total days of admission $(n=1368)$ & $4 \pm 2.58,3(2,34)$ & \\
\hline Number of days after termination $(n=1368)$ & $2.15 \pm 1.77,2(1,28)$ & \\
\hline $\begin{array}{l}\text { Indication } \\
\text { - } \quad \text { Maternal conditions } \\
\text { - } \quad \text { Fetal conditions } \\
\text { - } \quad \text { Other }\end{array}$ & & $\begin{array}{l}472(34.2) \\
601(43.5) \\
308(22.3)\end{array}$ \\
\hline 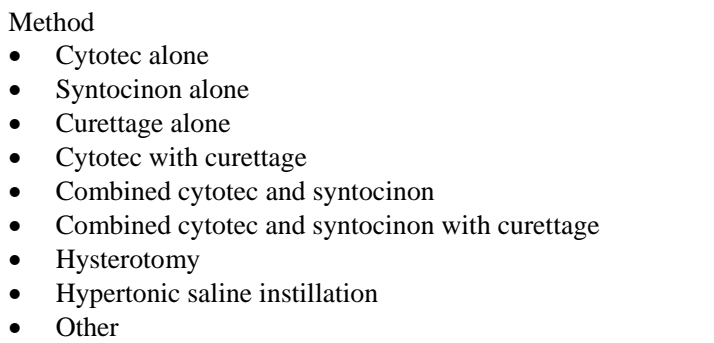 & & $\begin{array}{c}391(28.3) \\
18(1.3) \\
94(6.8) \\
382(27.7) \\
247(17.9) \\
88(6.4) \\
47(3.4) \\
91(6.6) \\
23(1.7)\end{array}$ \\
\hline
\end{tabular}

Other methods: combined surgical and medical interventions or menstrual regulation. 
Table 2. Dosage of cytotec usage for therapeutic abortion at Siriraj Hospital $(n=1105)$.

\begin{tabular}{ccc}
\hline Doses of cytotec usage & Number & Percent \\
\hline 100 micrograms every 6 hours & 12 & 1.1 \\
200 micrograms every 6 hours & 185 & 16.7 \\
200 micrograms every 8 hours & 3 & 0.3 \\
200 micrograms every 12 hours & 28 & 2.5 \\
400 micrograms every 6 hours & 586 & 53.1 \\
400 micrograms every 12 hours & 250 & 22.6 \\
$200-400$ micrograms every 4 - 8 hours & 41 & 3.7 \\
\hline
\end{tabular}

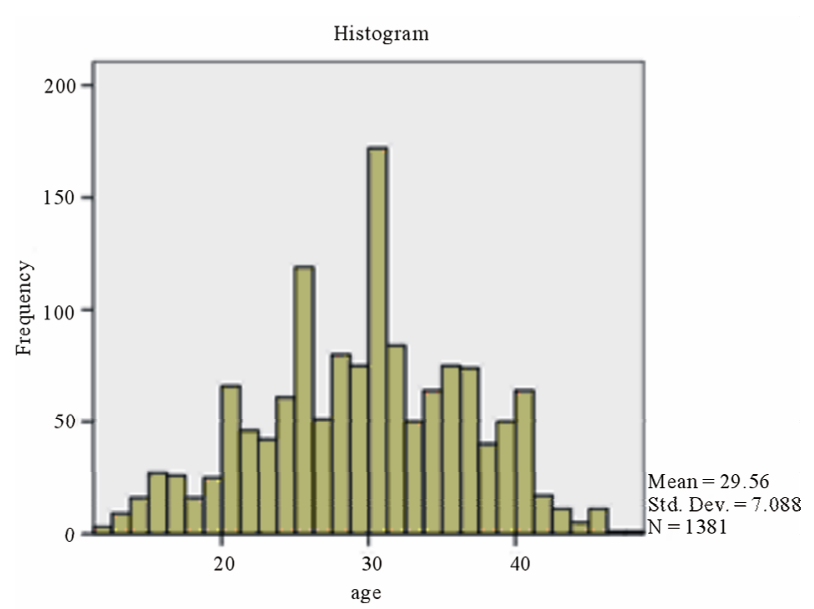

Figure 1. Maternal age of therapeutic abortion.

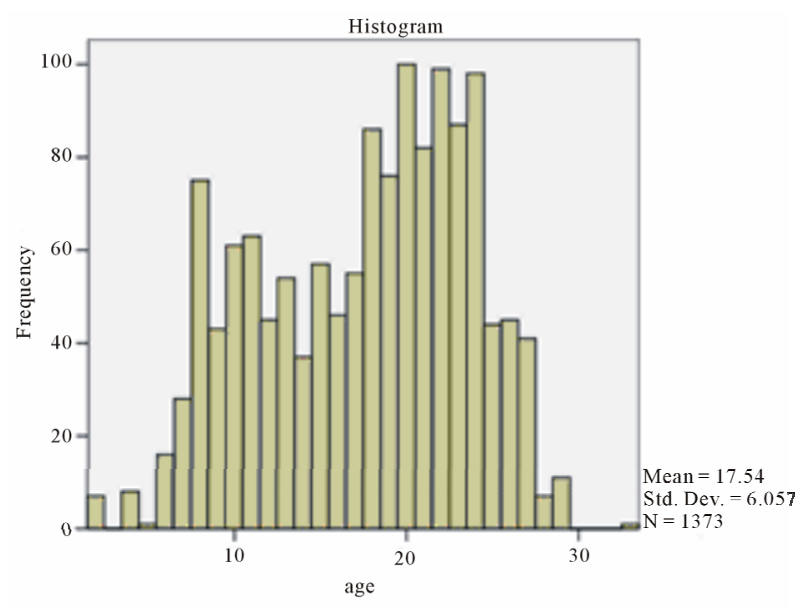

Figure 2. Gestational age of therapeutic abortion.

pital stay than those with curettage method (Figures 1314).

\section{DISCUSSION}

Therapeutic abortion is proposed when mother's health is

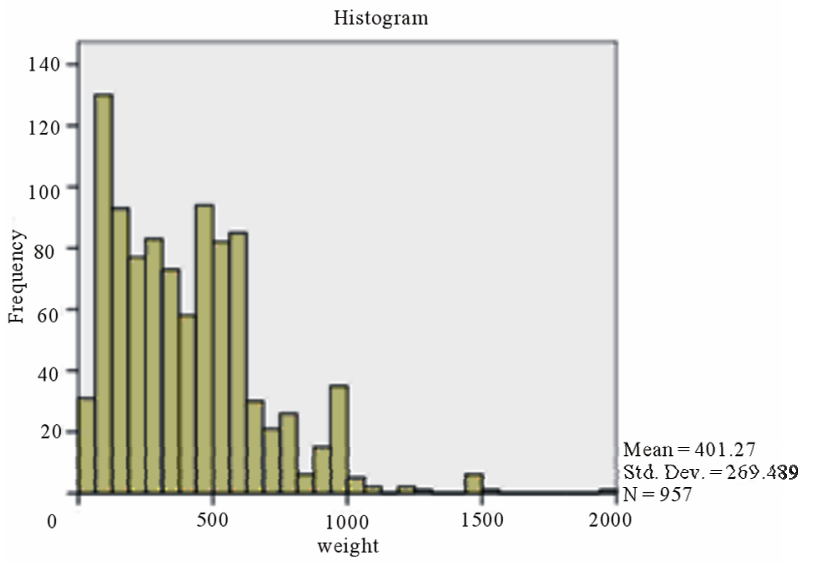

Figure 3. Fetal weight of therapeutic abortion.

threatened or fetus is unviable ex utero. Liberalization of abortion in Thailand is still illegal and can be only performed in indicated cases. The safest period of abortion is within the first 10 weeks of gestation in which women have the most choice of how the procedure is performed. [1] The complications are few in the first trimester of therapeutic abortion and anxious is reduced when intervention is performed at early gestational age.

Medical abortions are brought about by taking medications that end the pregnancy. The advantages of a first trimester medical abortion are non-invasive procedure; no surgical instrumental usage; no anesthesia performed; oral or injected drug usage and procedure resembling a natural abortion. The disadvantages of medical abortion are decreased effectiveness after the seventh week; required multiple visits to the doctor by the procedure; lasts longer bleeding after the abortion and presenting the contents of her womb as it is expelled [2].

First trimester surgical abortions are performed using vacuum aspiration, dilation and evacuation, suction dilation, vacuum curettage, or suction curettage. The advantages of first trimester surgical abortion are a one-day outpatient procedure, procedure taking only 10 - 15 min- 


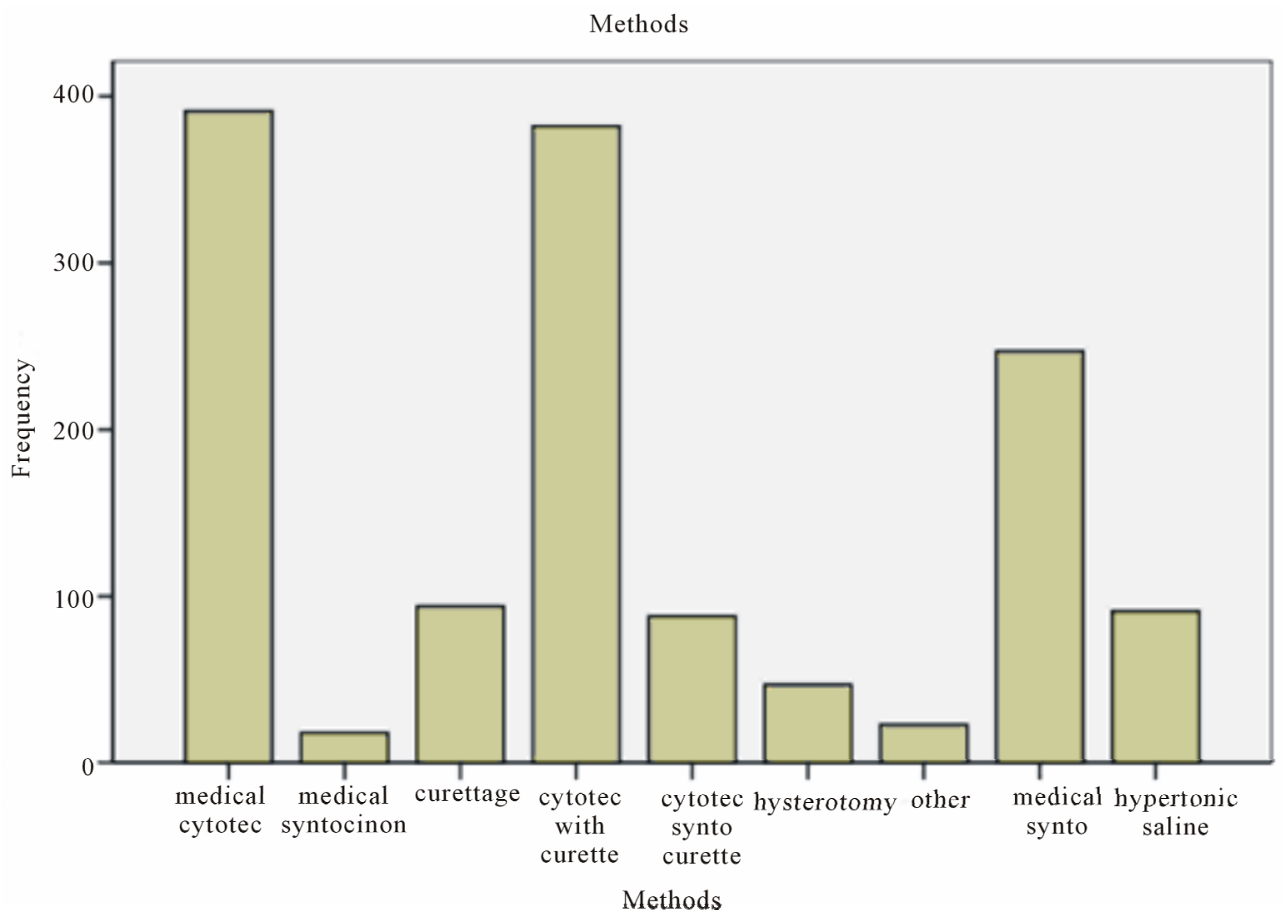

Figure 4. Methods of therapeutic abortion.

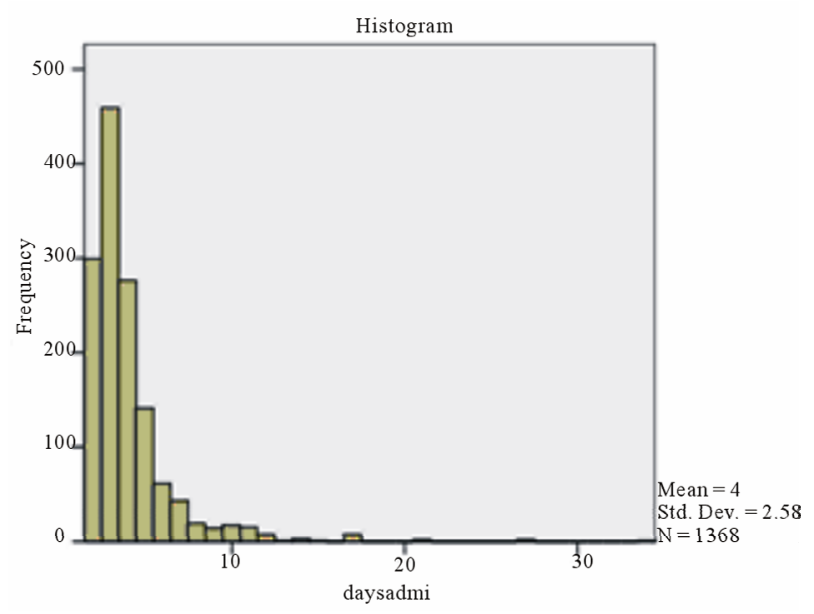

Figure 5. Day numbers of admission.

utes, bleeding lasting five days or less after the abortion, unseen the products after removal. The disadvantages of procedure are invasive, risk of infection, bleeding and perforation.

Higher rate of complications are found between 13 24 weeks of gestation of therapeutic abortion. From the study, therapeutic abortion was mostly performed during $17.54 \pm 6.06$ weeks of gestation. Abortion after 24 weeks of gestation is rare and usually correlated with maternal life threatening indication.

Maternal indications for therapeutic abortion in Siriraj Hospital are severe underlying diseases of pregnant women including heart disease, leukemia, severe pul-

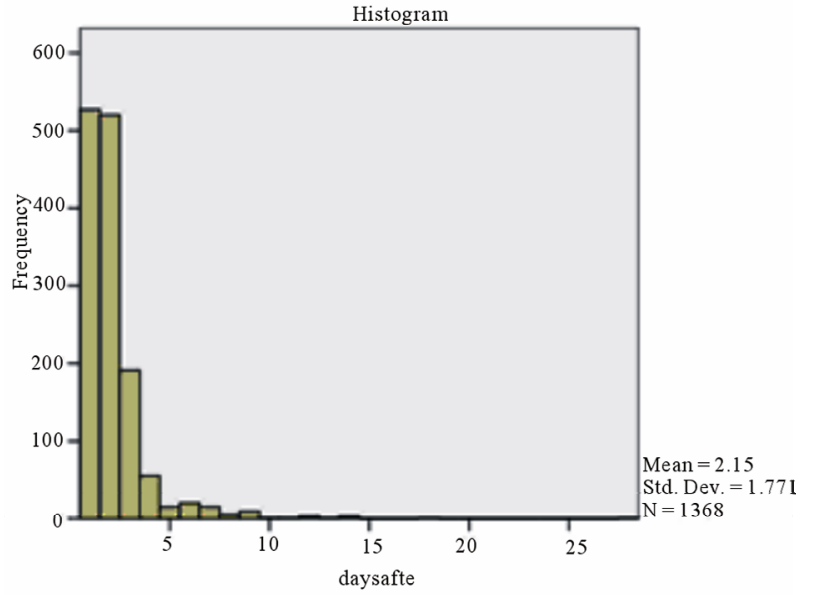

Figure 6. Day numbers after abortion.

monary disease; HIV infection and some psychological disorders. Pregnant women with HIV/AIDS can have their right for termination of pregnancy [3]. Although some indications such as HIV infection is not altered the maternal health, many couples decide for therapeutic abortion and following with tubal sterilization from this study.

The most common method of abortion was medical cytotec usage (28.3\%) and the least method of those was medical syntocinon usage (1.3\%). The appropriated method must be applied to the proper gestational age in order to increase the success rate. The average gestational age of abortion was about $17.54 \pm 6.05$ weeks of 


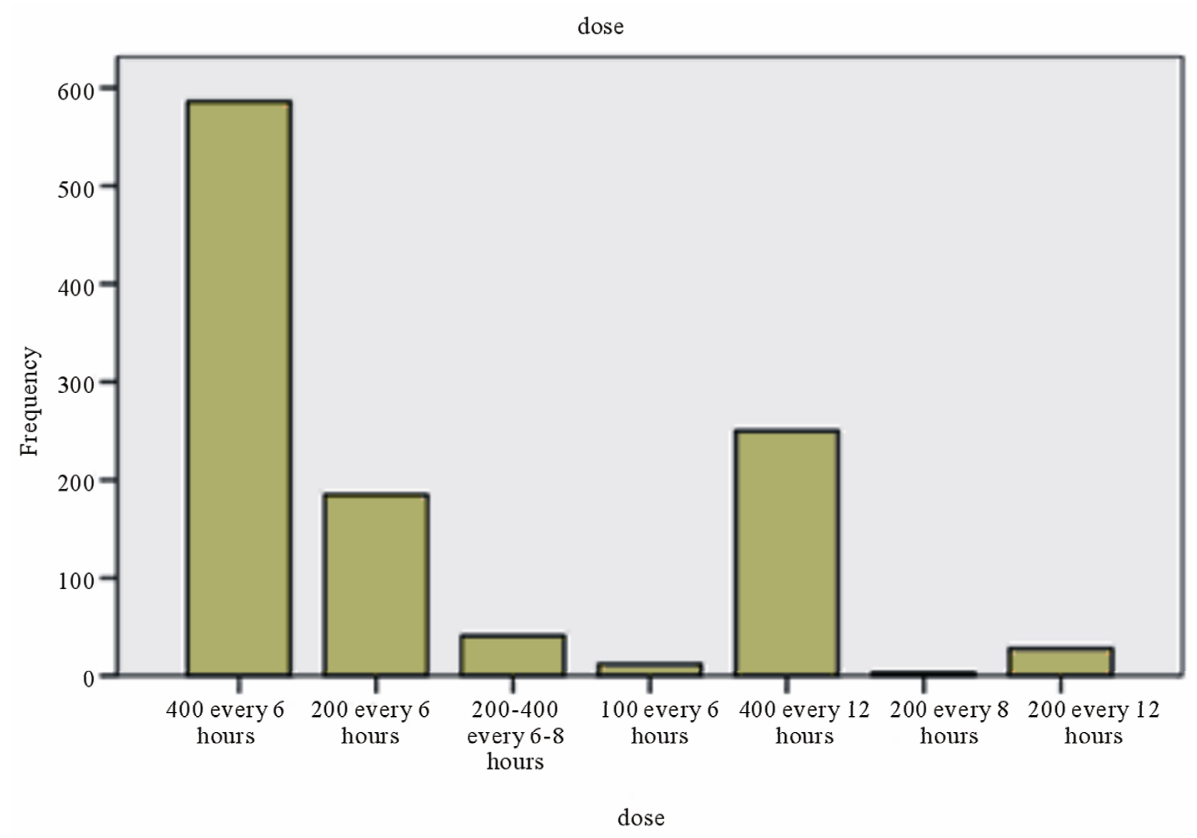

Figure 7. Dosage of cytotec usage for therapeutic abortion.

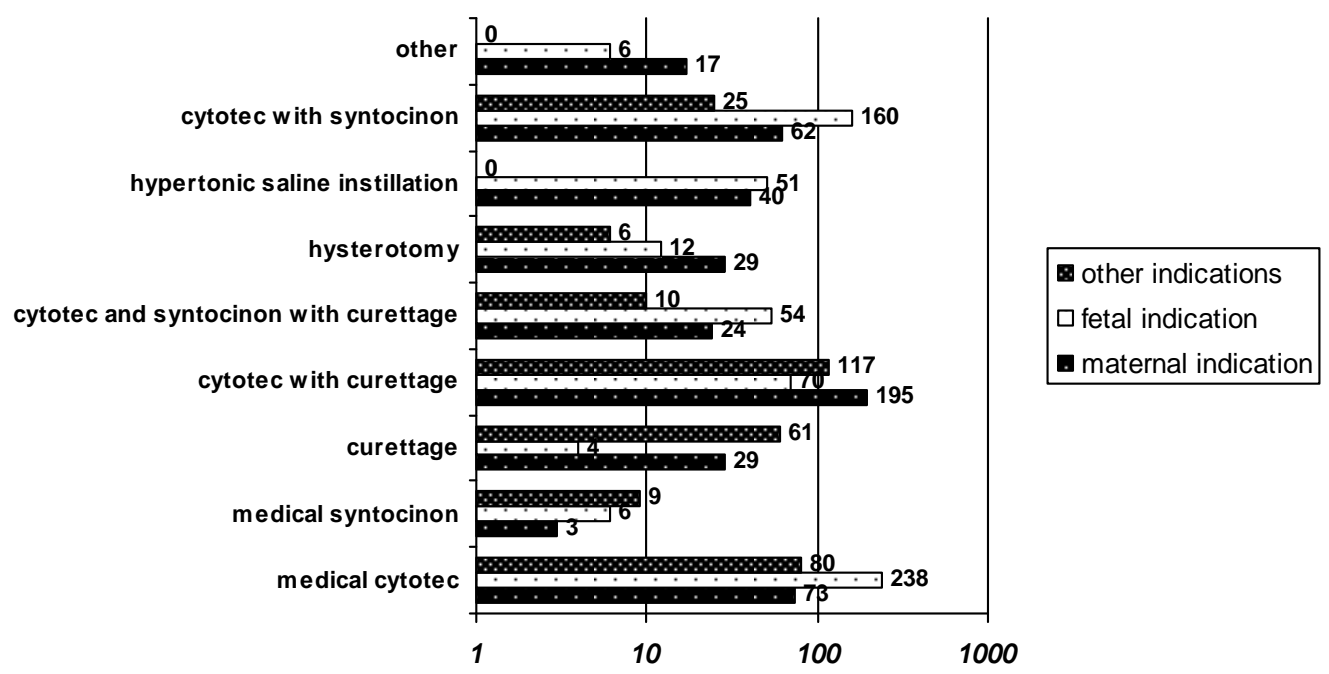

Figure 8. Association between indication for therapeutic abortion and methods of abortion Pearson Chi-square p-value $<0.001$.

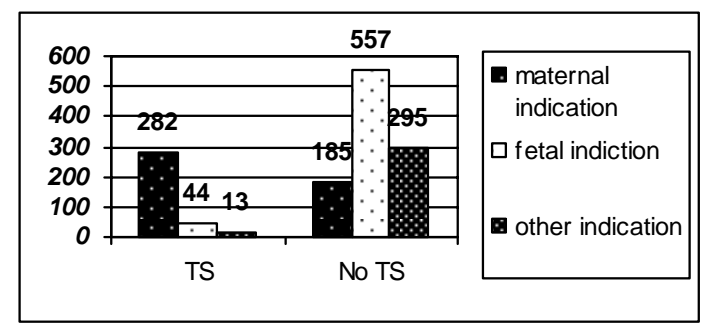

Figure 9. Association between indication for therapeutic abortion and TS Pearson Chi-square p-value < 0.001 .

gestation and syntocinon is the least effective method because few oxytocin receptors in myometrium are detected in that gestational age [4].

Menstrual regulation is performed during 5 to 7 weeks of gestation. The contents of the uterus are suctioned out through a thin $(3-4 \mathrm{~mm}$ ) plastic tube that is inserted through the undilated cervix. Suction is applied either by a bulb syringe or a small pump. [5] From the study, this method is mostly performed in maternal assault that we can terminate pregnancy in the earliest gestation. Therefore, psychic trauma and sexually transmitted diseases can be early prevented after the intervention. Serious complications resulting from abortions performed during this period are rare [6]. 


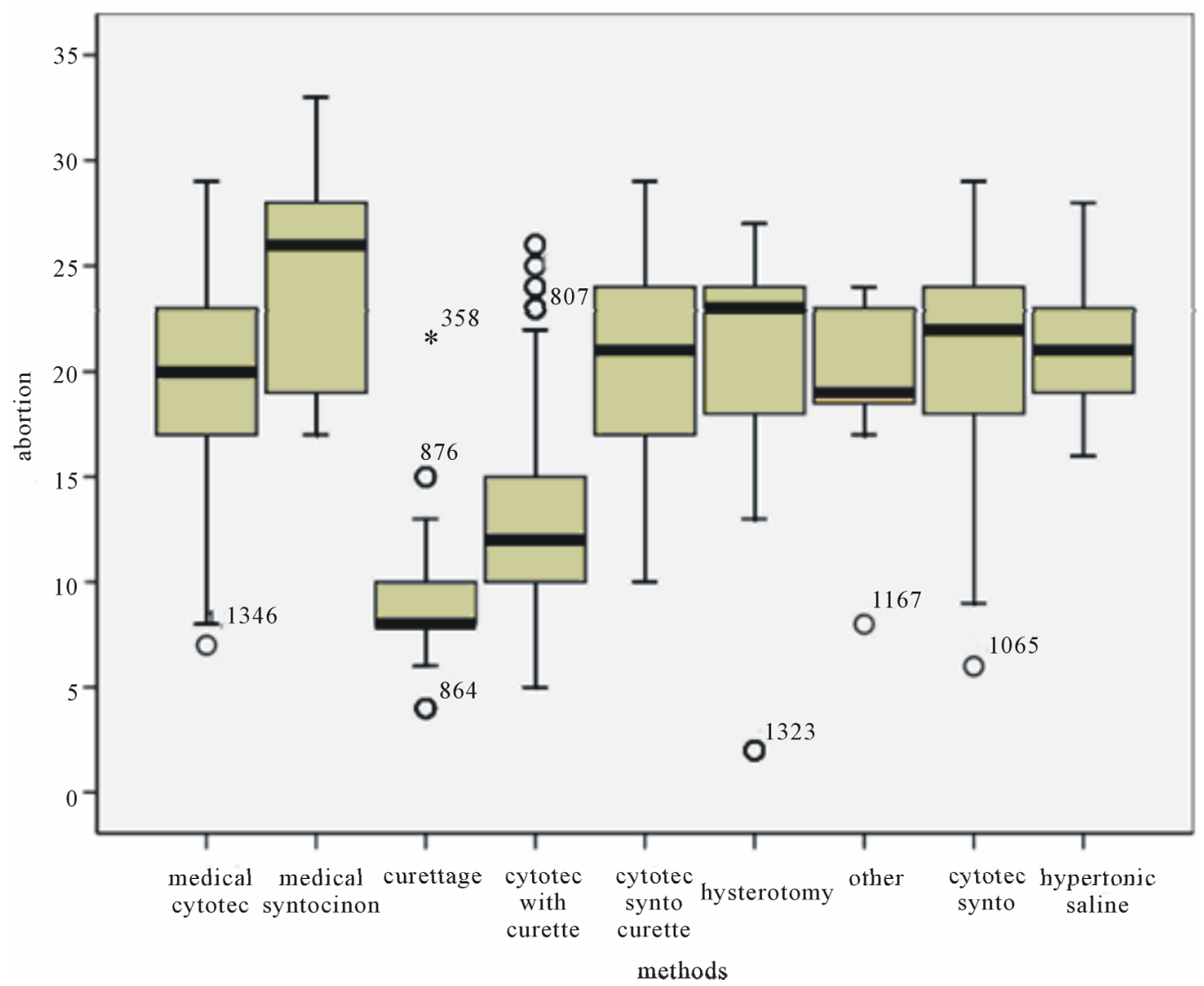

Figure 10. Association between gestational age and method of abortion.

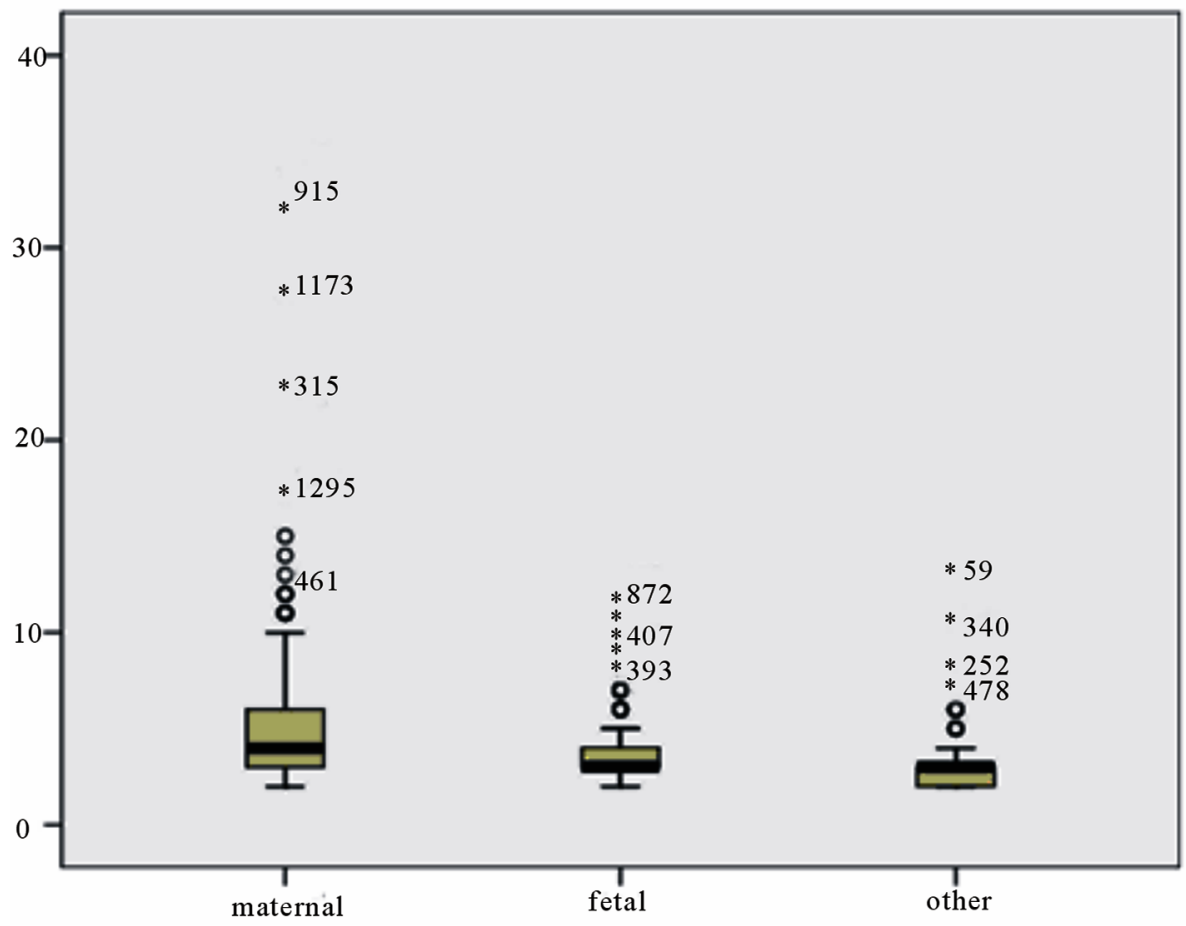

Figure 11. Association between indication and length of hospital stay. p-value $<0.001$ (Kruskal Wallis Test) Other indications include rupture of membranes, blighted ovum dead fetus in utero, inevitable abortion, missed abortion, anhydramnios and oligohydramnios. 


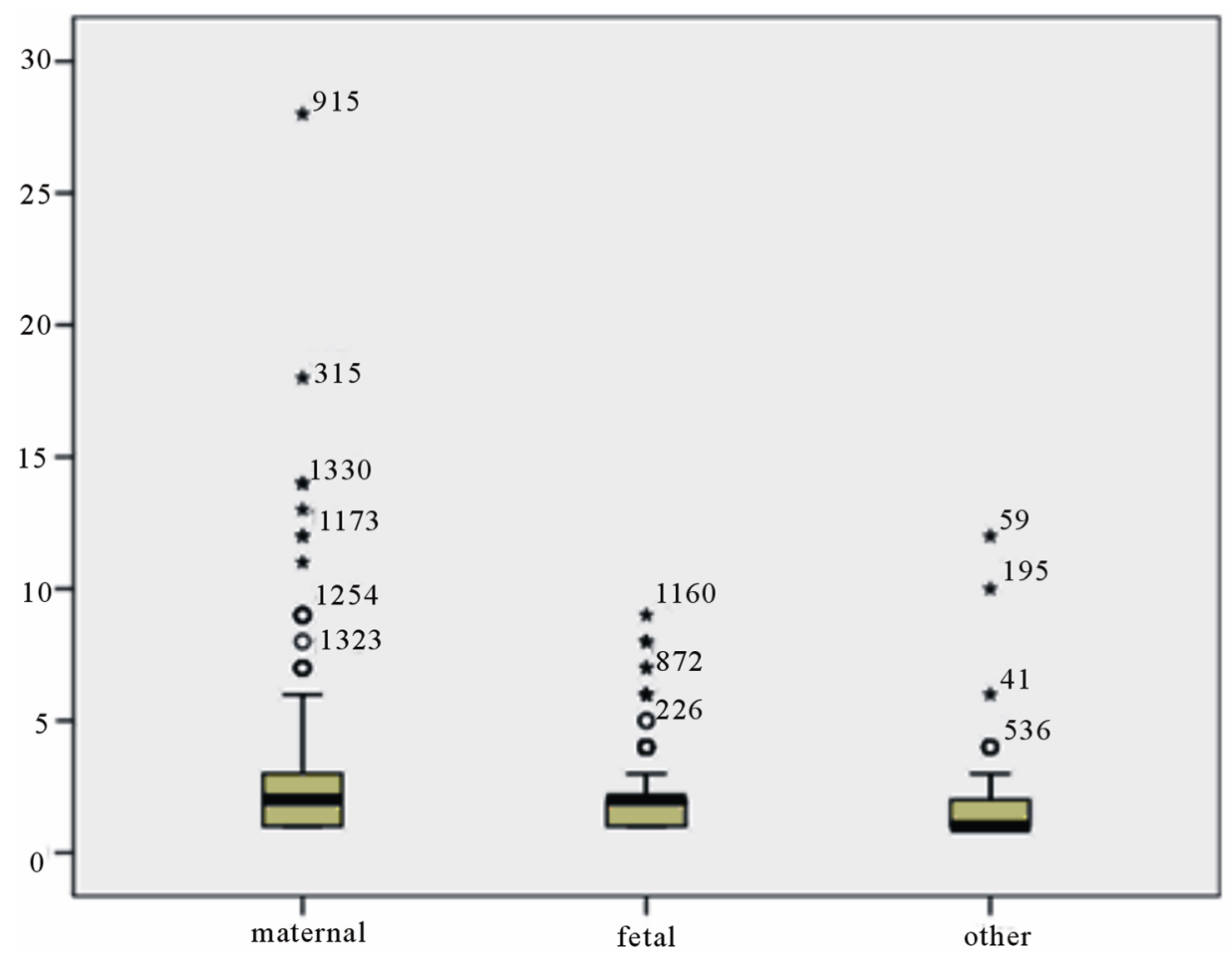

Figure 12. Association between indication and length of hospital stay after intervention p-value < 0.001 (Kruskal Wallis Test) Other indications include rupture of membranes, blighted ovum dead fetus in utero, inevitable abortion, missed abortion, anhydramnios and oligohydramnios.

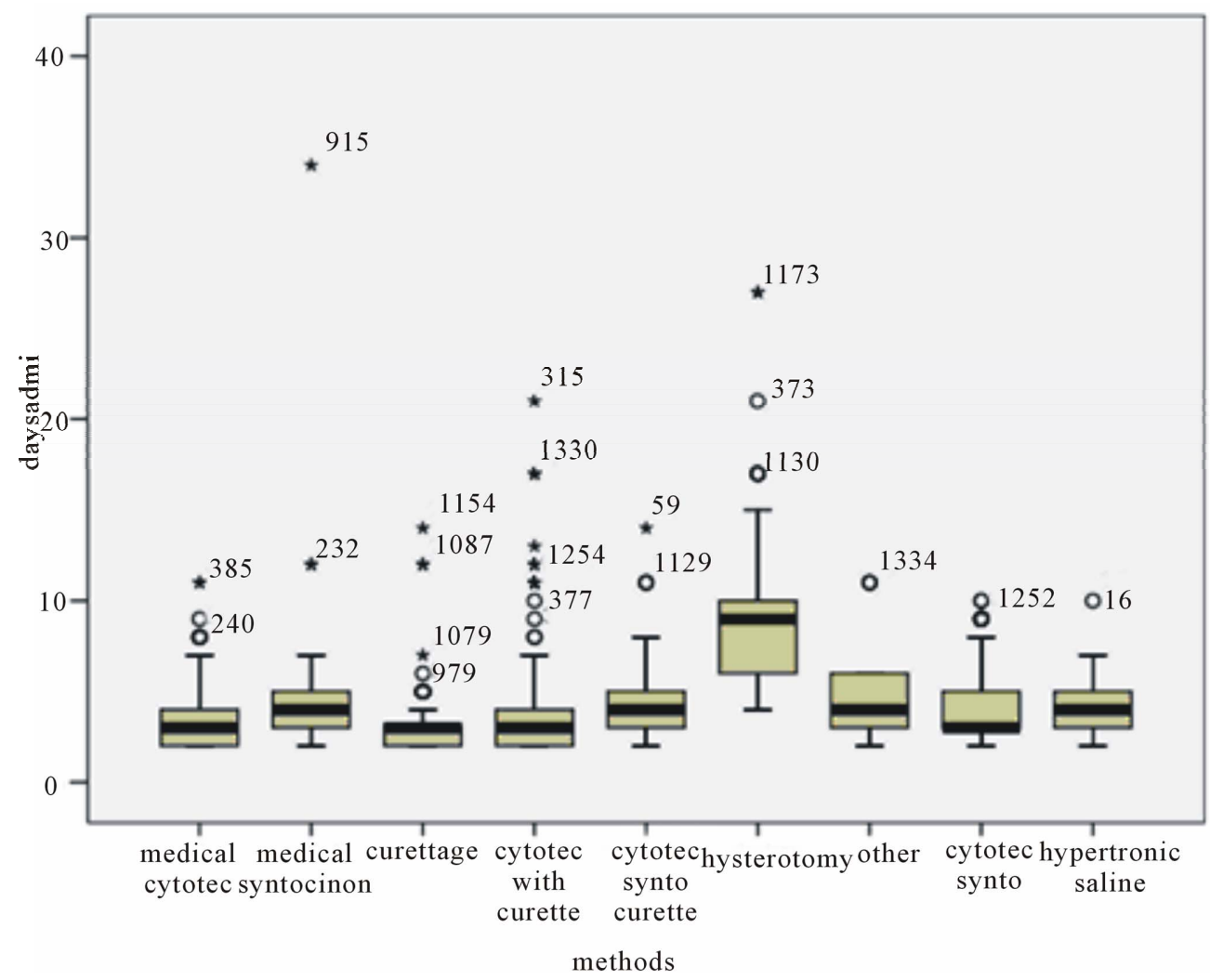

Figure 13. Association between method and length of hospital stay. p-value $<0.001$ (Kruskal Wallis Test). 


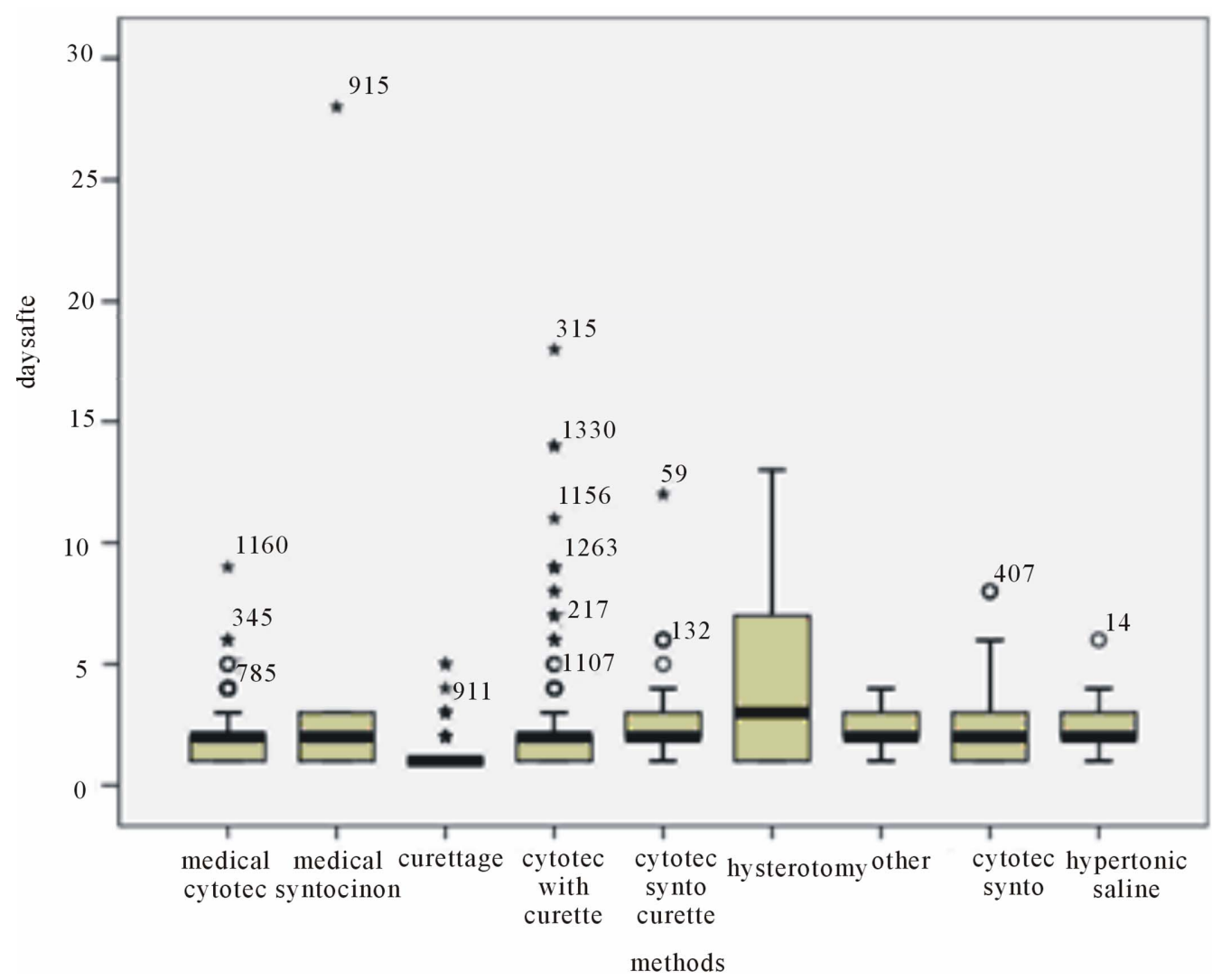

Figure 14. Association between method and length of hospital stay after intervention p-value $<0.001$ (Kruskal Wallis Test).

Dosage of cytotec usage was varied from 100 to 600 micrograms every 4 to 12 hours [7]. The common dosage of cytotec usage was 400 micrograms every 6 hours. Cytotec is off label drug used for abortion and is not recommended for women with ectopic pregnancy and IUD user [8].

Oxytocin administration for termination of pregnancy has been shown to have no significant efficacy during the first trimester [9]. The less efficacy is related to the poor oxytocin receptor which rarely found in the myometrium during early pregnancy. However, the efficacy is increased in the second trimester as the higher receptors in advanced gestation. From this study, oxytocin was clearly efficient in the second and third trimester.

Second trimester abortion may be inevitable from chromosomal abnormalities after genetic testing. Medical abortion by cytotec can be proceeded but not for all cases. Pregnancy with advance gestational age with suspected of survived fetus may require surgical method of hypertonic saline instillation. Salt water solution is injected into the uterus to induce fetal death. Fetal necrotic tissue is later released and formed a precursor of prostaglandin synthesis then contractions begin, and within eight to 72 hours the woman delivers the fetus.

Surgical interventions are relevant to the higher risk of
Table 3. Indications for therapeutic abortion.

\begin{tabular}{|c|c|}
\hline - $\quad$ Missed abortion & $2(0.1)$ \\
\hline - Anhydramnios & $22(1.6)$ \\
\hline - Oligohydramnios & $11(0.8)$ \\
\hline Total & $1381(100)$ \\
\hline - $\mathrm{PIH}$ & $22(1.6)$ \\
\hline - Heart disease & $34(2.4)$ \\
\hline - Renal diseasse & $3(0.2)$ \\
\hline - Hematologic disease & $5(0.4)$ \\
\hline - $\quad$ SLE & $13(0.9)$ \\
\hline - Malignancy or tumor & $44(3.2)$ \\
\hline - $\quad$ Other & $11(0.8)$ \\
\hline Fetal indications & $601(43.5)$ \\
\hline - Fetal thalassemia major & $184(13.4)$ \\
\hline - Chromosomal abnormalities & $158(11.5)$ \\
\hline - Fatal structural abnormalities & $244(17.7)$ \\
\hline - TTTS & $2(0.1)$ \\
\hline - $\quad$ Fetal risk & $13(1.0)$ \\
\hline Other indications & $308(22.3)$ \\
\hline - DFIU & $267(19.3)$ \\
\hline - Inevitable abortion & $6(0.4)$ \\
\hline
\end{tabular}


Table 4. Association between gestational age and method of abortion.

\begin{tabular}{cc}
\hline Method & GA (week) mean \pm SD \\
\hline Cytotec & $19.51 \pm 4.55$ \\
Syntocinon & $23.94 \pm 4.67$ \\
Curettage & $9.07 \pm 2.85$ \\
Cytotec with curettage & $13.10 \pm 4.94$ \\
Combined cytotec and syntocinon & $20.73 \pm 4.69$ \\
with curettage & $19.66 \pm 8.14$ \\
Hysterotomy & $31.00 \pm 4.04$ \\
Combined cytotec and syntocinon & $21.31 \pm 2.95$ \\
Hypertonic saline instillation & $19.74 \pm 3.46$ \\
Other & \\
\hline
\end{tabular}

p-value (one way ANOVA) $<0.001$.

Table 5. Association between indication, maternal age and gestational age of abortion.

\begin{tabular}{lcc}
\hline \multicolumn{1}{c}{ Method } & $\begin{array}{c}\text { Maternal age } \\
\text { (years) mean } \pm \text { SD }\end{array}$ & $\begin{array}{c}\text { GA(weeks) } \\
\text { Mean } \pm \text { SD }\end{array}$ \\
\hline Maternal indication & $26.88 \pm 7.33$ & $14.72 \pm 5.47$ \\
Fetal indication & $31.18 \pm 6.63$ & $21.17 \pm 3.96$ \\
Other indication & $30.50 \pm 6.36$ & $14.73 \pm 6.55$ \\
\hline
\end{tabular}

p-value (one way ANOVA) $<0.001$.

procedure, requirement of overnight stay in a hospital, requirement of anesthesia in some cases and the higher cost of the procedure. From the study length of hospital stay and those after the procedure was highest in women underwent the procedure of hysterotomy. The complication after surgical intervention is higher than medical intervention. The rate of complications increases as the pregnancy progresses.

Complications from abortions can include uncontrolled bleeding, infection, blood clots accumulating in the uterus, a tear in the cervix or uterus, missed abortion where the pregnancy continues and incomplete abortion where some materials from the pregnancy remain in the uterus. However, the pregnancy is usually ended without complication and without altering future fertility.
Pre- and post-abortion counseling is important in helping a woman resolve any questions she may have about having the procedure. Unintended pregnancy or rape cases are still found in Thailand and abortion is legal. Law and culture are the important issues to discuss in many countries therefore unsafe abortion can be decreased.

\section{REFERENCES}

[1] Hodgson, J.E. (1975) Major complications of 20,248 consecutive first trimester abortions: Problems of fragmented care. Advances in Planned Parenthood, 9, 52-59.

[2] Kulier, R., Kapp, N., Gülmezoglu, A.M., Hofmeyr, G.J., Cheng, L. and Campana, A. (2011) Medical methods for first trimester abortion. Cochrane Database of Systematic Reviews, 9, CD002855. doi:10.1002/14651858.CD002855.pub4

[3] de Bruyn, M. (2003) Safe abortion for HIV-positive women with unwanted pregnancy: A reproductive right. Reproductive Health Matters, 11, 152-161. doi:10.1016/S0968-8080(03)02297-3

[4] Kimura, T., Takemura, M., Nomura, S., Nobunaga, T., Kubota,Y., Inoue, T., et al. (1996) Expression of oxytocin receptor in human pregnant myometrium. Endocrinology, 137, 780-785. doi:10.1210/en.137.2.780

[5] Lichtenberg, E.S. and Paul, M. (2013) Surgical abortion prior to 7 weeks of gestation. Contraception, 88, 7-17. doi:10.1016/j.contraception.2013.02.008

[6] Hossain, A., Maddow-Zimet, I., Singh, S. and Remez, L. (2012) Menstrual regulation, unsafe abortion, and maternal health in Bangladesh. Issues in Brief (Alan Guttmacher Institute), 3, 1-8.

[7] Kulier, R., Kapp, N.,Gülmezoglu, A.M., Hofmeyr, G.J., Cheng, L. and Campana, A. (2011) Medical methods for first trimester abortion. The Cochrane Library, 9, CD002855. doi:10.1002/14651858.CD002855.pub4

[8] Sirakov, M. (2012) "Off label” use of some medicinal products. Part II. "Off label” use of misoprostol. Akush Ginekol (Sofiia), 51, 50-54.

[9] Nygaard, I.H.,Valbø, A., Heide, H.C. and Kresovic, M. (2011) Is oxytocin given during surgical termination of first trimester pregnancy useful? A randomized controlled trial. Acta Obstetricia et Gynecologica Scandinavica, 90, 174-178. doi:10.1111/j.1600-0412.2010.01025.x 